\title{
Structural Analysis of a Freight Wagon with Composite Walls
}

\author{
ALEXANDRU IONUT PATRASCU ${ }^{1,2}$, ANTON HADAR ${ }^{2,3,4}$, STEFAN DAN PASTRAMA ${ }^{2,1 *}$ \\ ${ }^{1}$ Romanian Railway Authority, 393 Calea Grivitei, 010719, Bucharest, Romania \\ ${ }^{2}$ University Politehnica of Bucharest, Faculty of Industrial Engineering and Robotics, Department of Strength of Materials, 313 Splaiul \\ Independentei, 060042, Bucharest, Romania \\ ${ }^{3}$ Academy of Romanian Scientists, 54 Splaiul Independentei, 050085, Bucharest, Romania \\ ${ }^{4}$ Technical Sciences Academy of Romania, 26 Dacia Blvd., 010413, Bucharest, Romania
}

\begin{abstract}
The paper presents a numerical study regarding the mechanical response of the body of a freight wagon to the usual loads encountered during service. The main goal of the present research is to investigate the possibility to replace the steel walls of the wagon with walls made of laminated composites. In this way, the total mass of the wagon can be decreased, leaving room for supplementary load of goods. Finite element analyses of the wagon with steel walls is presented first, in order to show that most of the load is taken by the structure of the wagon, while the stresses in the walls are low. Further, composite plates with different thickness are studied to find the minimum value of thickness for which the displacements have values below a certain range. These thicknesses are further considered in the finite element analyses of the entire wagon with composite walls to investigate if the new walls significantly change the stresses in the vehicle structure. It was concluded that the replacement does not alter the stress state in the structure, and, consequently, it is a good solution for diminution of the total mass of the vehicle.
\end{abstract}

Keyword: Composite materials, finite element, freight wagon, von Mises stress, displacements

\section{Introduction}

Since its appearance, rail transport was considered one of the most important systems of transportation. In time, rail vehicles suffered a lot of changes in order to satisfy the customer needs. The first freight rail vehicles were very simple, equipped with two axles and a low transport capacity. Most of the new freight wagons are equipped with four axles and two bogies, which means more transport capacity. Today, freight rail vehicles are complex and offer much more advantages such as: high volume of transport, increased running speeds, safety, etc.

In most cases, rail wagons present a standard and simple construction composed of axles, chassis, bogies and vehicle body. Depending on the type of wagon, the vehicle body can have different shapes and sizes, being designed to support and carry different goods [1]. The vehicle body is a structural element made of steel sheets and beams. In the last years, researches were undertaken with the purpose to reinforce or to replace the steel walls with composite ones in order to increase corrosion protection, to reduce the weight of the wagon, to ease the unloading of the wagon in winter conditions and also for an easier management of the freight wagons during exploitation [2].

Wróbel et al. [3] presented a methodology for detection of damages in laminate panels used as assemblies and sub-assemblies of a freight wagon. Large fiberglass reinforced laminated panels were tested using thermography. The panels were heated and further examined through a thermal imaging camera. The authors concluded that, in the case of large panels as those to be used for freight wagons, thermography has some disadvantages, like the fact that large area should be heated and also that the panels should be dismantled from the wagon. They suggest the use of vibration methods, where the damage is detected based on the analysis of changes in vibrations that occur due to the damage. Płaczek et al. [2] discussed the problems that appear during exploitation of freight wagons designed for coal transport, the main one being corrosion of the wagon's body shell. They proposed the use of composite panels made of epoxy resin reinforced with fiberglass, mounted on the body shell using blind rivet nuts and further painted using an anticorrosion agent. The authors designed CAD models of several types of

\footnotetext{
*email: stefan.pastrama@upb.ro
} 
freight wagons in order to perform their strength analysis, but they do not present similar analyses for the new composite replacement structures. They concluded that there is a possibility to use smaller crosssections profiles and thickness of the wagon body sheets could be reduced. Also, additional composite panels mounted to the wagon's body shell will bring an additional stiffness to the structure. A similar analysis, without and with composite panels reinforcement was presented in [4]. Modelling of threepoint and four-point bending test of multilayer composite materials used to renovate the hull of freight wagons and a subsequent finite element analysis (FEA) of the scaled freight wagon hull's sidewall was presented in [5]. The authors propose a reinforcement of the sidewall using composites made of five layers, each layer being a combination of epoxy resin and $34 \%$ carbon fibers with plain weave. The obtained results showed that a $4 \mathrm{~mm}$ composite panel reinforcement on the sidewall of the freight wagon's hull will reduce the stresses with $20 \%$. Buchacz et al. [6] presented a FEA to study the influence of fiber arrangement of a laminated composite material on the values of stresses in the composite panel of a modified freight wagon. Following the numerical analyses, the authors obtained the method of assembly of the composite panels to the side panel of the wagon that minimizes the stresses occurring in the composite plate. Also, they showed that the proposed arrangement reduces the unfavorable influence of the mechanical reaction of the joining elements on the values of stresses in the outer layers of the composite material. Kosobudzki et al [7] proposed also the increase of the stiffness of the load space walls in a freight wagon body by using composite panels. They analyzed the mechanical behavior in the combination steel sheet and glass-epoxy composite for two types of connection between the two materials: screwed and with adhesive. Further, the obtained solution was tested as a solution for the door of the freight wagon box. Application of composite panels in the process of renovating the body of a wagon was investigated also by Sobek et al. [8]. They presented fatigue tests of composite panel samples fixed to a metal plate using stainless steel nuts and screws. Teste were done by cyclic loads applied to test samples using a pneumatic cylinder. The authors emphasized the advantage of using a combination of a composite panel with a metal plate instead of metal alone. Attempts to replace metal components of railway wagons were done also for other sub-structures like brake blocks [9] or wagon suspension system [10].

This paper presents the structural study of an Eaos type wagon body, having as the main goal replacement of the steel walls with composite ones, to the difference of the above-mentioned papers in which only a reinforcement with composite plates was considered as a solution. The composite walls can be glued to the steel poles of the vehicle body, after removing the steel sheets or can be fixed with rivets or screws. With the solution investigated in the present research, the reduction of the vehicle mass is also obtained using lighter materials, in order to increase its load.

\section{Materials and methods}

The studied vehicle is an EAOS four axles open wagon (Figure 1), used to transport coal, ore, stone, scrap metal, timber and other similar raw materials. The main characteristics of the wagon are [11]:

- $\quad$ Track gauge (spacing of the rails): $1435 \mathrm{~mm}$;

- $\quad$ Length of the body vehicle: $12790 \mathrm{~mm}$;

- Width of the body vehicle: $2770 \mathrm{~mm}$;

- Height of the body vehicle: $1890 \mathrm{~mm}$;

- Area of the body vehicle surface: $36 \mathrm{~m}^{2}$;

- Mass of vehicle: $22 \mathrm{t}$;

- Maximum axle load: $20 \mathrm{t}$.

The $22 \mathrm{t}$ Eaos rail vehicle is able to carry a maximum load of $58 \mathrm{t}$. Most of the transported load is transmitted through the steel sheet floor to the chassis. In most cases, a small part of the load is transmitted all over the side and front walls, which is why the steel walls can be replaced with lighter materials such as composite materials. 


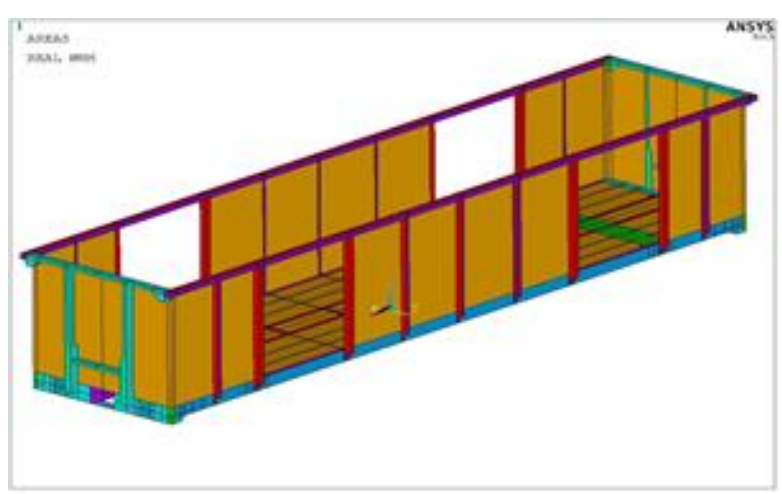

Figure 1. The studied vehicle body

\section{Finite element analyses of the present structure}

In order to use new lighter materials for the structure of the vehicle walls, the entire wagon structure was first verified by applying a series of loads, according to the European standards. During the application of these loads, the evolution of the mechanical stresses in the structure of the vehicle was determined.

In accordance with the European standard 12663-2:2010 [12] the structure of the studied rail vehicle was subjected to the following main loads:

Compressive force at the buffers level - $2000 \mathrm{kN}$ (1000 kN for each buffer);

Compressive force at the couple level $-2000 \mathrm{kN}$;

Tensile force at the couple level - $1500 \mathrm{kN}$;

Maximum vertical load - $58 \mathrm{t}$.

Numerical analyses were performed using the Finite Element Method (FEM), using the software Ansys 14.5 [13]. Considering that the vehicle is built largely from regular geometric elements, shell elements were used. Pictures of the finite element model having 411078 nodes and 138504 elements with the average side of $35 \mathrm{~mm}$ are shown in Figure 2.

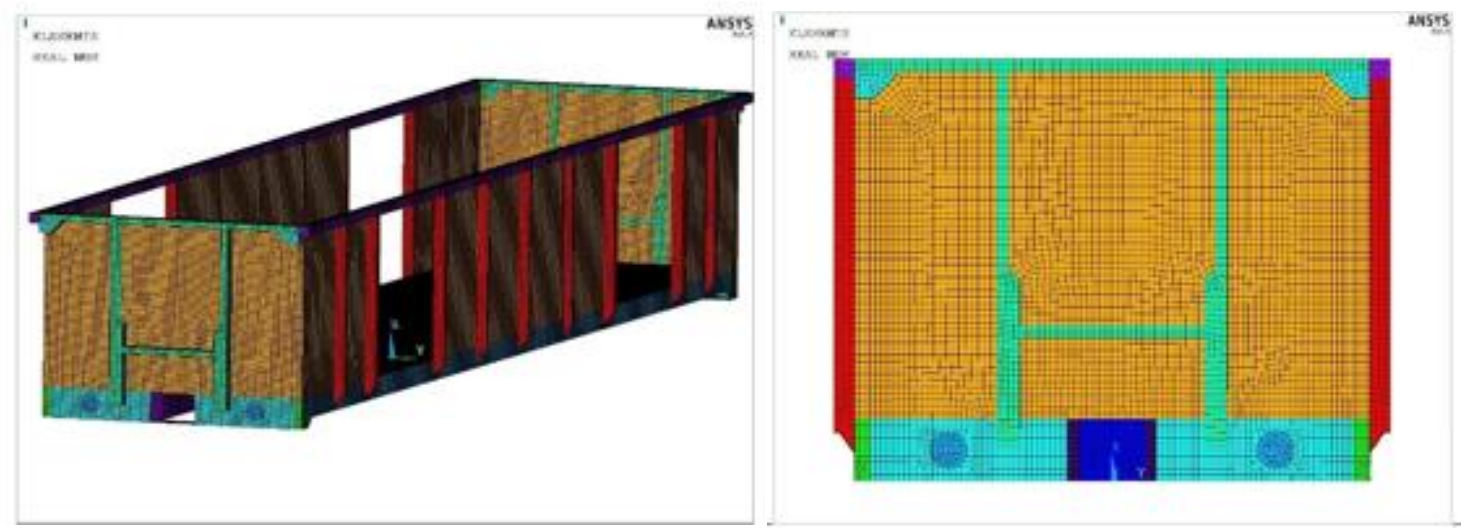

Figure 2. The finite element model of the studied structure

\section{Compressive force at the buffers level}

The test analysis for obtaining the stress and strain states due to the compressive force at the buffers level simulates the transfers of forces from one vehicle to another during operating time. Rail vehicles can be maneuvered by pushing, using a locomotive. During this time, longitudinal forces are transmitted from one vehicle to another through vehicles buffers to the chassis. In case of this analysis, forces of $2000 \mathrm{kN}$ ( $1000 \mathrm{kN}$ for each buffer) were applied in the buffers area to obtain the stress and strain states. The distribution of the von Mises equivalent stress in the entire structure is shown in Figure 3 and a detail in the chassis area is presented in Figure 4 [14]. From the results, it can be noticed that most of the applied forces act on the chassis of the vehicle. At the same time, the values of the equivalent stress are below the maximum allowed limit for the used steel which is $355 \mathrm{MPa}$. 


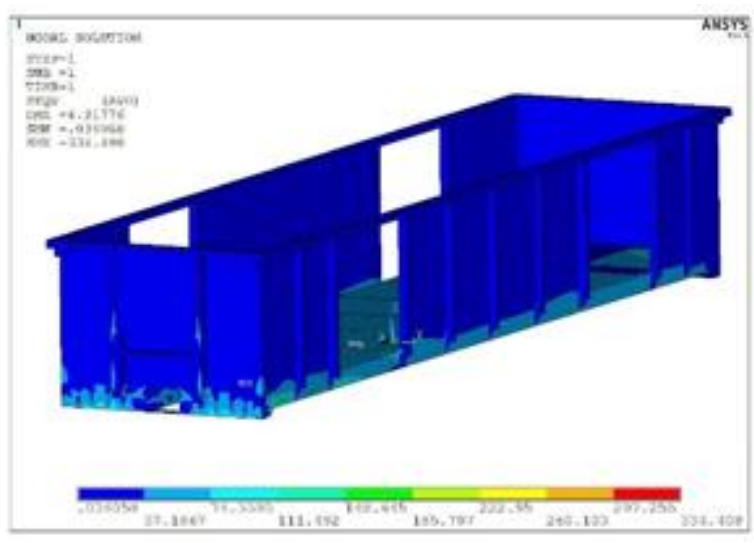

Figure 3. Compressive force at the buffers level - von Mises stress - overview

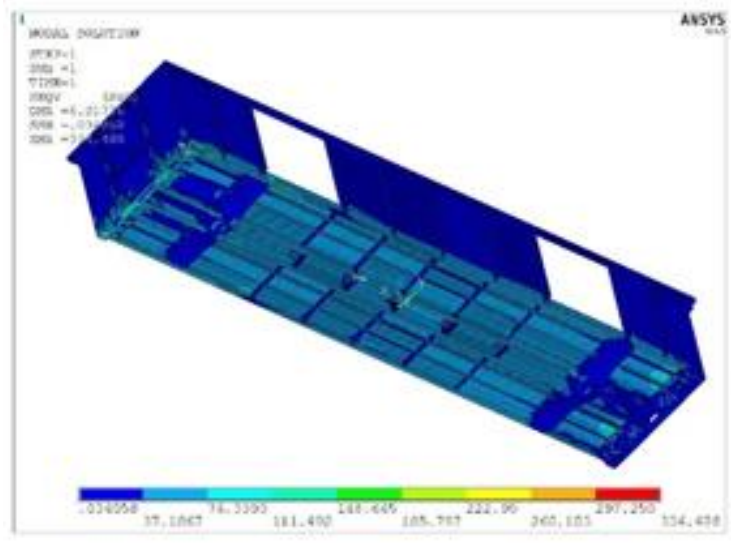

Figure 4. Compressive force at the buffers level - von Mises stress - chassis area

\section{Compressive force at the couple level}

Many rail vehicles are equipped with automatic coupling which facilitate the coupling operation of the railway vehicles, saving thus time. The couplings are devices mounted in the middle end area of the railway vehicles, transmitting the longitudinal forces from one rail vehicle to another. For this type of analysis, a force of $2000 \mathrm{kN}$ was applied in the couple area. The force acts directly at the crossbeam level, which is a massive element of the chassis. Figure 5 and Figure 6 present the equivalent von Mises stress distribution in this load case [14].

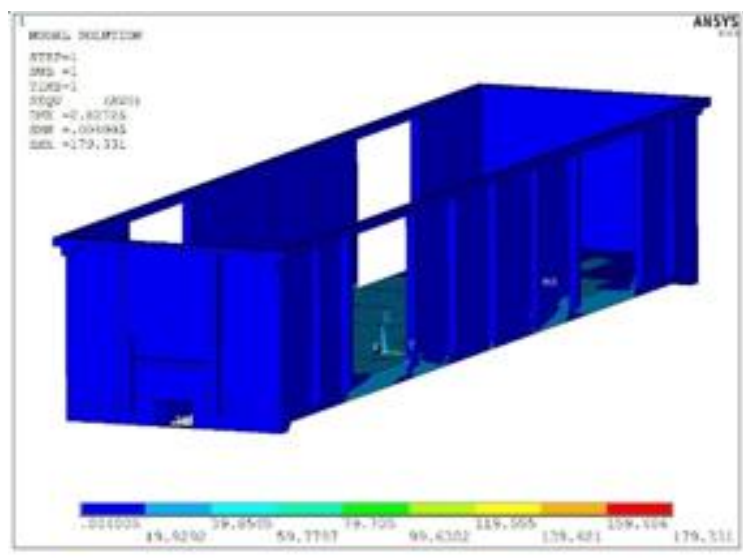

Figure 5. Compressive force at the couple level - von Mises stress - overview

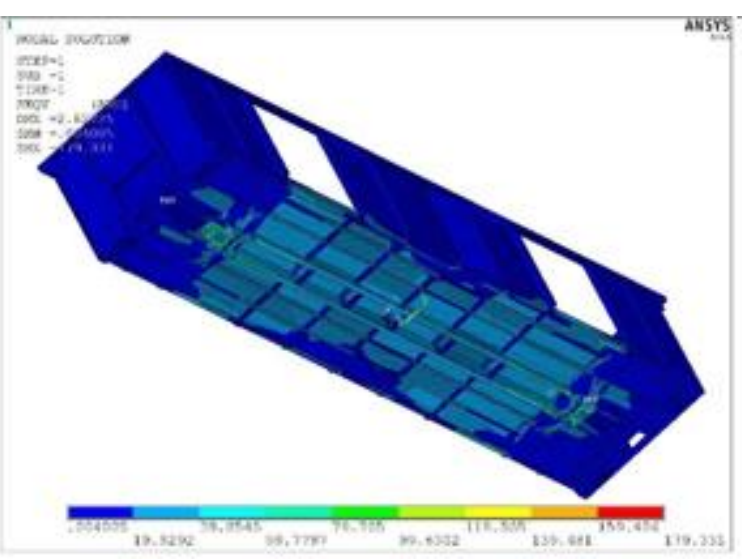

Figure 6. Compressive force at the couple level - von Mises stress - chassis area

As displayed above, in this case, the values of the von Mises equivalent stress are below the limit of $355 \mathrm{MPa}$, the maximum value obtained for this load case being around $180 \mathrm{MPa}$. From Figure 6, it can be observed that the force acts mainly at the chassis level, the stress values in the walls being low.

\section{Tensile force at the couple level}

Application of a tensile force at the couple level simulates the most common case in train traffic when several wagons are towed by a locomotive and the traction force of the locomotive is transmitted through the couples from the first to the last vehicle of the train. In this situation, the standard requires a tensile force of $1500 \mathrm{kN}$ to be applied at the couple area of the rail vehicles structure.

The results of this simulation are presented in Figure 7 and Figure 8 [14]. As in the previous load cases, the stress values did not exceed the stress limit of the material. Also, at the walls level, the stress values are very low, which shows that the steel walls can be replaced with lighter materials. 


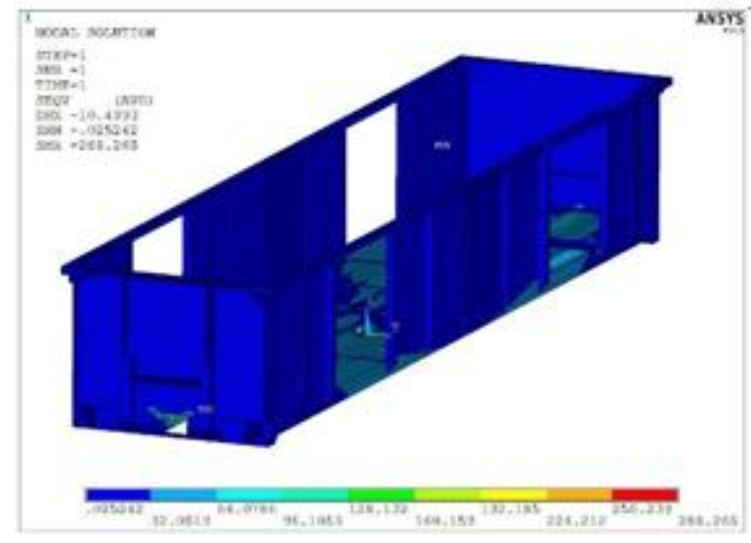

Figure 7. Tensile force at the couple level - von Mises stress - overview

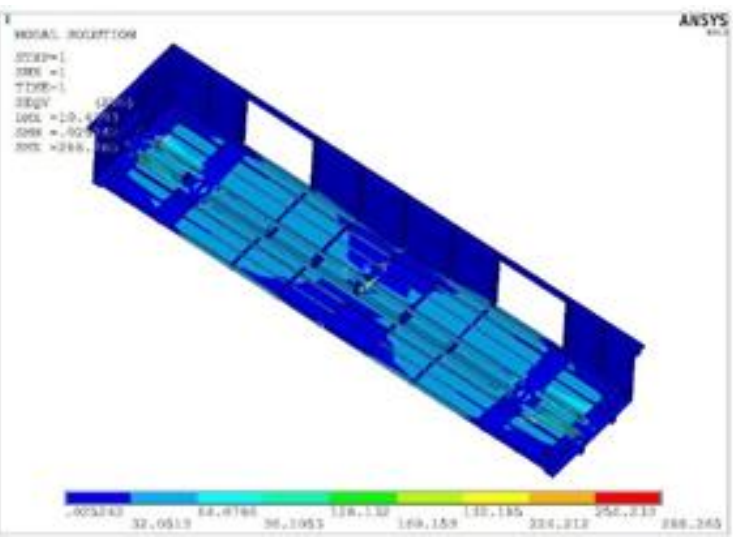

Figure 8. Tensile force at the couple level - von Mises stress - chassis area

\section{Maximum vertical load}

Freight rail vehicles are designed to carry heavy loads, compared to their mass. The transport capacity depends on several factors such as: vehicle type, maximum axle load, maximum load supported by the structure, volume of transport etc. The studied rail vehicle has a mass of $22 \mathrm{t}$ and can carry a maximum load of $58 \mathrm{t}$ [11]. The simulation of the maximum vertical load reproduces the behavior of the vehicle structure in case of loading the wagon with the maximum transport load. That is why a load of $58 \mathrm{t}$ was uniformly applied on the floor of the vehicle. Also loads of $2 \mathrm{t}$ were applied to the front walls and $5 \mathrm{t}$ to the side walls, to simulate the pressure of the load on the walls of the wagon.

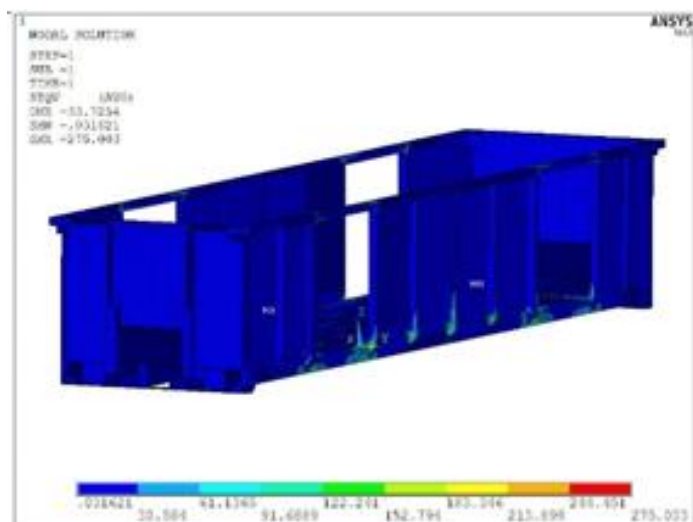

Figure 9. Maximum vertical load - von Mises stress - overview

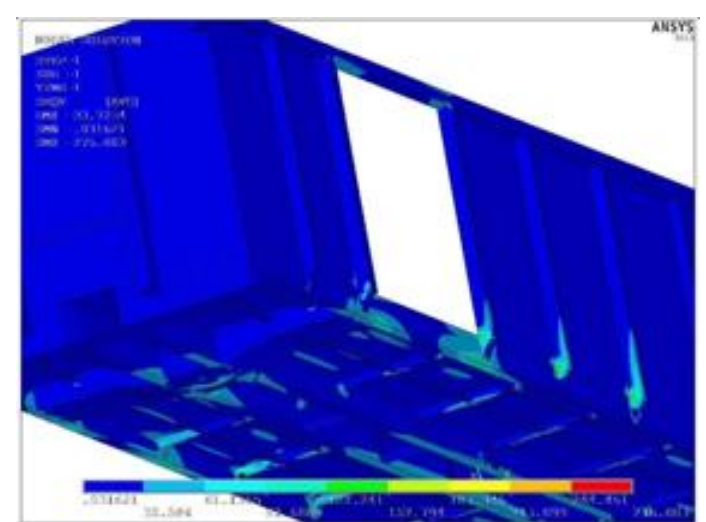

Figure 10. Maximum vertical

load - von Mises stress - chassis area

Figure 9 and Figure 10 present the distribution of the von Mises stress due to the action of the maximum vertical load [14]. Except the local singularities, it can be seen that the values of the mechanical stresses are low. Analyzing Figure 10, it can be seen that the effect of the applied load on the wall poles is not significant, showing that the replacement of the steel walls with lighter materials is feasible.

\section{Numerical analysis of small-scale composite material}

To replace the steel walls with composite ones in order to reduce the weight and without affecting the structure of the vehicle, first a finite element analysis was performed for the structure of the vehicle without the steel walls, in the loading case of compressive force at buffer level (paragraph 3.1). The distribution of the von Mises equivalent stress in this case is shown in Figure 11. Analyzing the obtained results, it can be seen that the stress distribution is not changed significantly after removing the steel 
walls. In other words, the structure of the wagon takes most of the load; the same conclusion can be drawn for all the other loading cases.

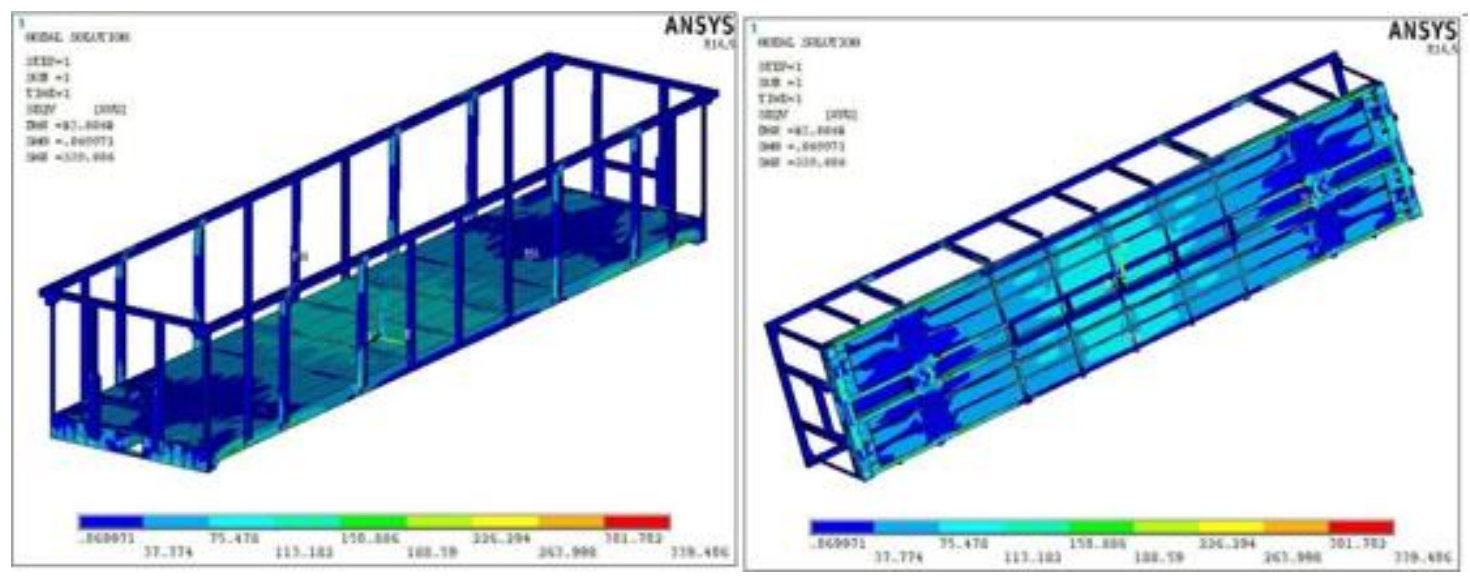

Figure 11. Wagon structure without steel

walls - von Mises stress - compressive loads at buffer level

From the analyses shown in the previous paragraph, it can be seen that, for all loads applied according to the European standards, the stress state in the wagon walls is reduced, and, consequently, a replacement of the steel sheets with composite sheets is perfectly feasible.

Further, numerical analyses were undertaken to determine the minimum thickness of the composite sheet. To reduce the computation time, numerical analyses were performed on a small square plate with the area of $1 \mathrm{~m}^{2}$, constrained on all edges. A composite material made of polyester resin reinforced with glass fibers was considered. The mechanical properties used in the numerical analyses are listed in Table $1[15]$.

Table 1. Mechanical properties of the composite material

\begin{tabular}{cccccccccc}
\hline & $\begin{array}{c}\text { Young's moduli } \\
{[\mathbf{M P a}]}\end{array}$ & & $\begin{array}{c}\text { Shear moduli } \\
{[\mathbf{M P a}]}\end{array}$ & & Poisson's ratios & & $\begin{array}{c}\text { Density } \\
{\left[\mathbf{g} / \mathbf{c m}^{3}\right]}\end{array}$ \\
\hline $\mathrm{E}_{1}$ & $\mathrm{E}_{2}$ & $\mathrm{E}_{3}$ & $\mathrm{G}_{1}$ & $\mathrm{G}_{2}$ & $\mathrm{G}_{3}$ & $v_{12}$ & $v_{23}$ & $v_{31}$ & $\rho$ \\
\hline 16500 & 15200 & 7200 & 6000 & 5000 & 3150 & 0.129 & 0.118 & 0.33 & 1.524 \\
\hline
\end{tabular}

\section{Results and discussions}

Calculating the surface of the walls and using the maximum load of the vehicle, it results a maximum force of about $1 \mathrm{t} / \mathrm{m}^{2}$. First, a finite element analysis of a square $5 \mathrm{~mm}$ thick steel plate with the area of $1 \mathrm{~m}^{2}$ was performed, using the load mentioned above. The equivalent von Mises stresses and maximum displacement are shown in Figure 12 and Figure 13 respectively. Based on these results, the optimum thickness of the composite material was determined. The results obtained for different thicknesses of the new material, namely $5 \mathrm{~mm}, 10 \mathrm{~mm}$ and $15 \mathrm{~mm}$ are presented in terms of equivalent von Mises stress and maximum displacements in Figures 14-19. 


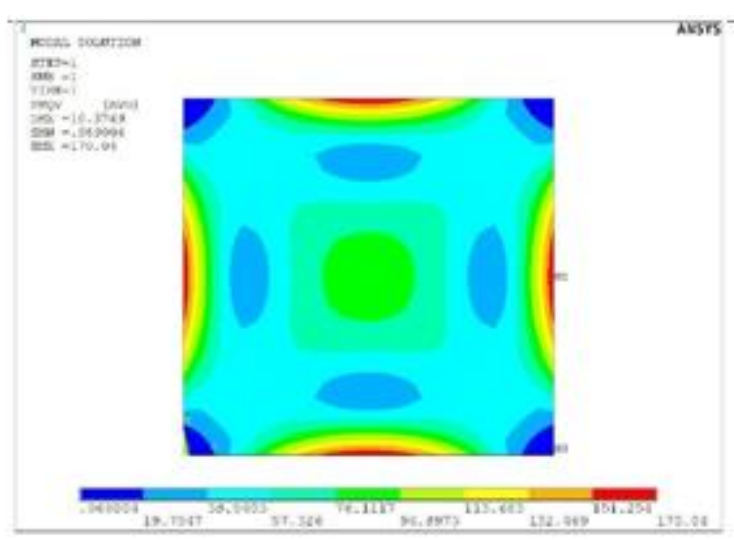

Figure 12. Von Mises stress distribution in the $5 \mathrm{~mm}$ thick steel plate

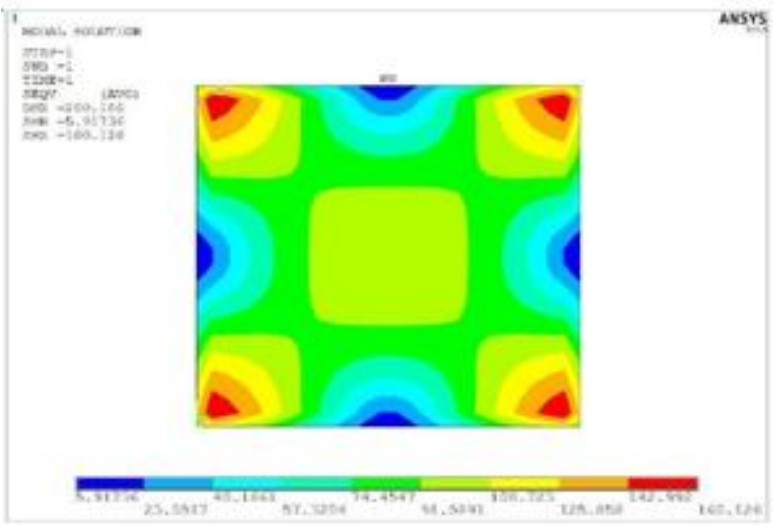

Figure 14. Von Mises stress distribution in the $5 \mathrm{~mm}$ thick composite plate

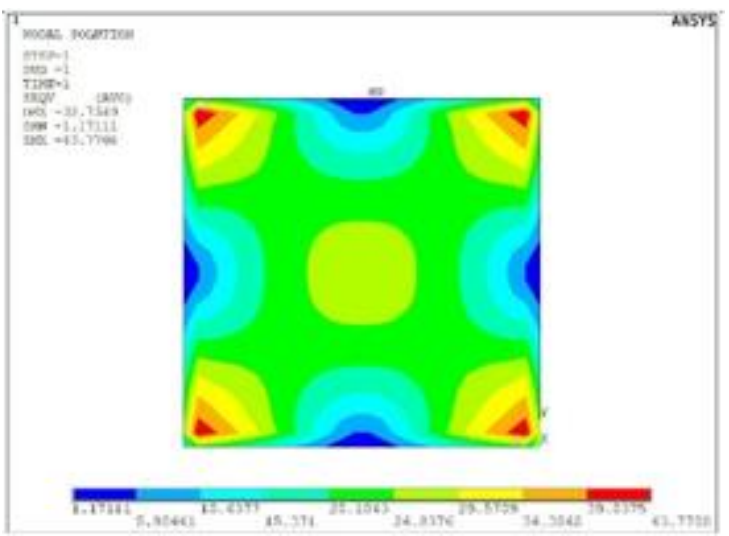

Figure 16. Von Mises stress distribution in the $10 \mathrm{~mm}$ thick composite plate

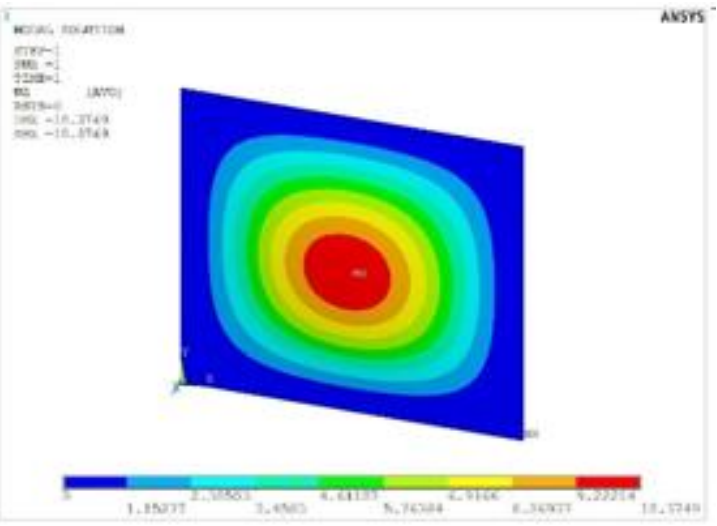

Figure 13. Distribution of maximum displacement in the $5 \mathrm{~mm}$ thick steel plate

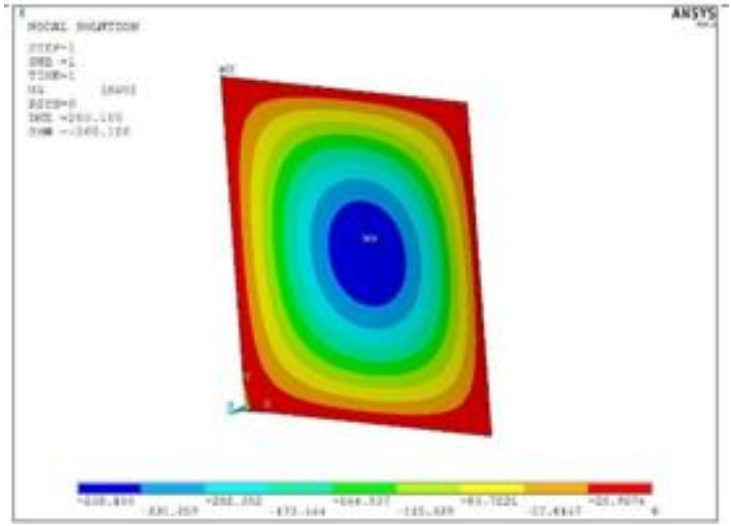

Figure 15. Distribution of maximum displacement in the $5 \mathrm{~mm}$ thick composite plate

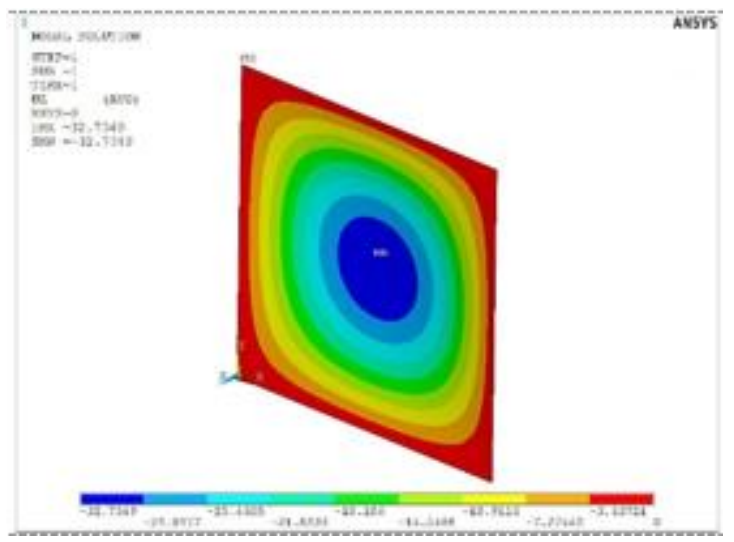

Figure 17. Distribution of maximum displacement in the $10 \mathrm{~mm}$ thick composite plate 


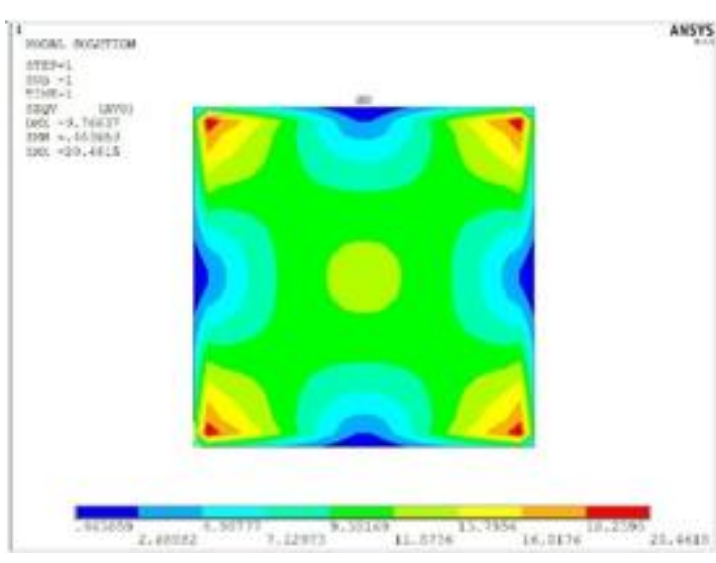

Figure 18. Von Mises stress distribution in the $15 \mathrm{~mm}$ thick composite plate

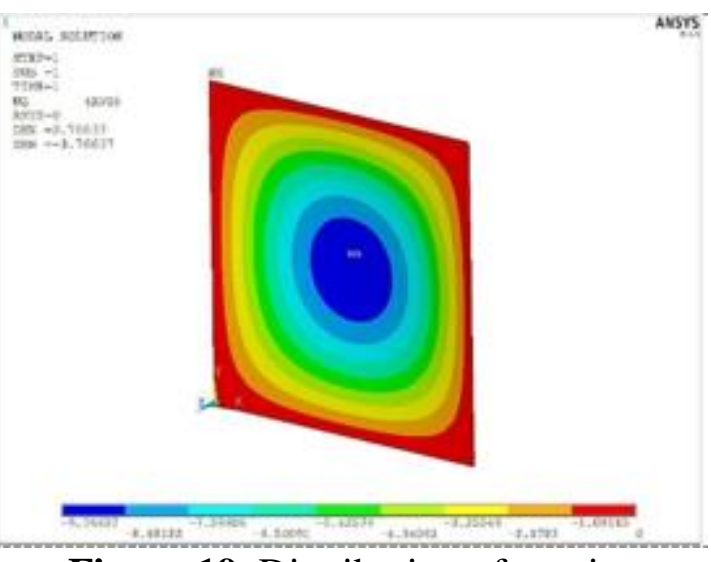

Figure 19. Distribution of maximum displacement in the $15 \mathrm{~mm}$ thick composite plate

The main results for the composite plates with different thicknesses are listed in Table 2.

Table 2. Composite plate results: Maximum von Mises stress and maximum displacement

\begin{tabular}{cccc}
\hline $\begin{array}{c}\text { Composite sheet thickness } \\
{[\mathrm{mm}]}\end{array}$ & $\begin{array}{c}\text { Composite Sheet mass } \\
{[\mathbf{k g}]}\end{array}$ & $\begin{array}{c}\text { Maximum von Mises } \\
\text { stress [MPa] }\end{array}$ & $\begin{array}{c}\text { Maximum displacement } \\
{[\mathbf{m m}]}\end{array}$ \\
\hline 5 & 7.62 & 160.12 & 260.16 \\
\hline 10 & 15.24 & 43.77 & 32.73 \\
\hline 15 & 22.86 & 20.46 & 9.76 \\
\hline
\end{tabular}

As can be seen, for the thickness of $5 \mathrm{~mm}$, the total displacement has a high value. Thus, it can be concluded that the replacement of the metal sheet with composite sheet is possible only using a thickness of at least $10 \mathrm{~mm}$.

\section{Analysis of the structure with composite walls}

Starting from the total surface of the wagon walls, which is $20.606 \mathrm{~m}^{2}$, without lateral opening doors and $34.511 \mathrm{~m}^{2}$ with the opening doors sheet, a comparative study reveals that the use of the composite material for the walls of the wagon leads to a significant reduction of up to about $80 \%$ for the actual mass of the vehicle, as it can be inferred from Table 3.

Table 3. Mass of walls - comparative results between steel and composite sheets

\begin{tabular}{|c|c|c|c|c|c|}
\hline \multicolumn{2}{|c|}{$\begin{array}{l}\text { Sheet thickness } \\
{[\mathrm{mm}]}\end{array}$} & \multicolumn{2}{|c|}{$\begin{array}{c}\text { Steel sheet walls mass } \\
{[\mathrm{Kg}]}\end{array}$} & \multicolumn{2}{|c|}{$\begin{array}{c}\text { Composite sheet walls mass } \\
{[\mathrm{Kg}]}\end{array}$} \\
\hline Steel & Composite & Without doors & $\begin{array}{l}\text { With } \\
\text { doors }\end{array}$ & Without doors & $\begin{array}{l}\text { With } \\
\text { doors }\end{array}$ \\
\hline \multirow{3}{*}{5} & 5 & \multirow{3}{*}{803.63} & \multirow{3}{*}{1345.92} & 157.01 & 262.97 \\
\hline & 10 & & & 314.04 & 525.94 \\
\hline & 15 & & & 471.05 & 788.92 \\
\hline
\end{tabular}

The loading case with the most elevated stresses and which is most encountered in wagon maneuvers and circulation is the load of compressive force at the buffers level. For this case of loading, simulations were performed to evaluate the effect obtained after replacing the steel sheet of the vehicle walls with $10 \mathrm{~mm}$ and $15 \mathrm{~mm}$ thickness composite sheets. The maximum equivalent stress and the maximum total displacement in these cases are discussed further.

In order to reduce calculation time, the analyses were done only a quarter of the vehicle, due to symmetry. A $1000 \mathrm{kN}$ force was applied in each buffer area, according to the standards. During the analysis, additional forces were applied to the walls to simulate the action of the load, as mentioned in the previous paragraphs. 
The results for $10 \mathrm{~mm}$ composite sheet thickness are presented in Figures 20 - 22. As expected, based on previous results, the application of composite panels to the wagon walls did not significantly change the stresses in the vehicle structure. The maximum displacement value was recorded, as expected, in the median area of one of the composite plates (Figure 22). In this case, considering the wagon doors, the use of composite walls decreases the mass with about $820 \mathrm{~kg}$.

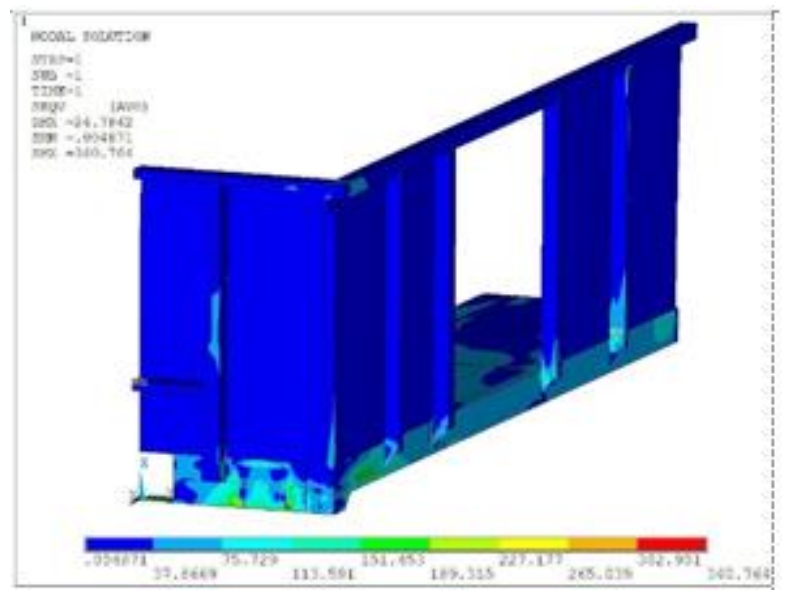

Figure 20. Von Mises stress distribution for $10 \mathrm{~mm}$ thick composite walls

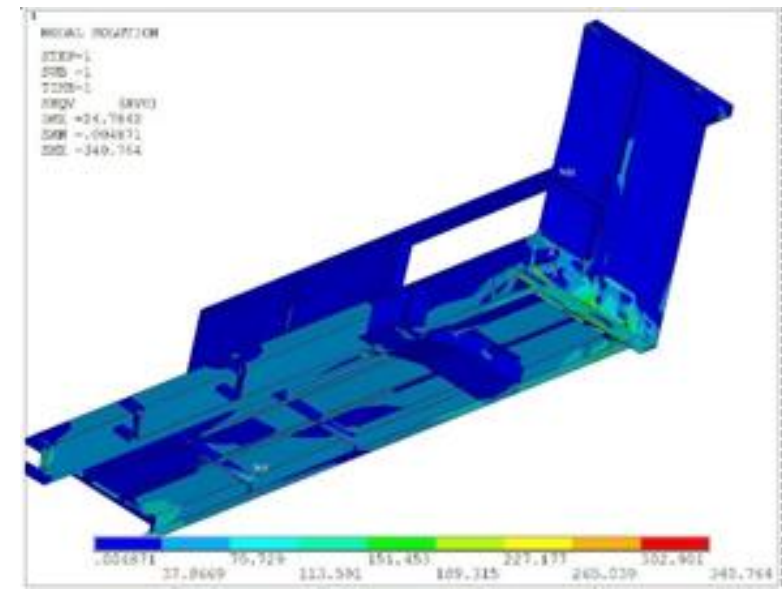

Figure 21. Von Mises stress distribution in the chassis area for $10 \mathrm{~mm}$ thick composite walls

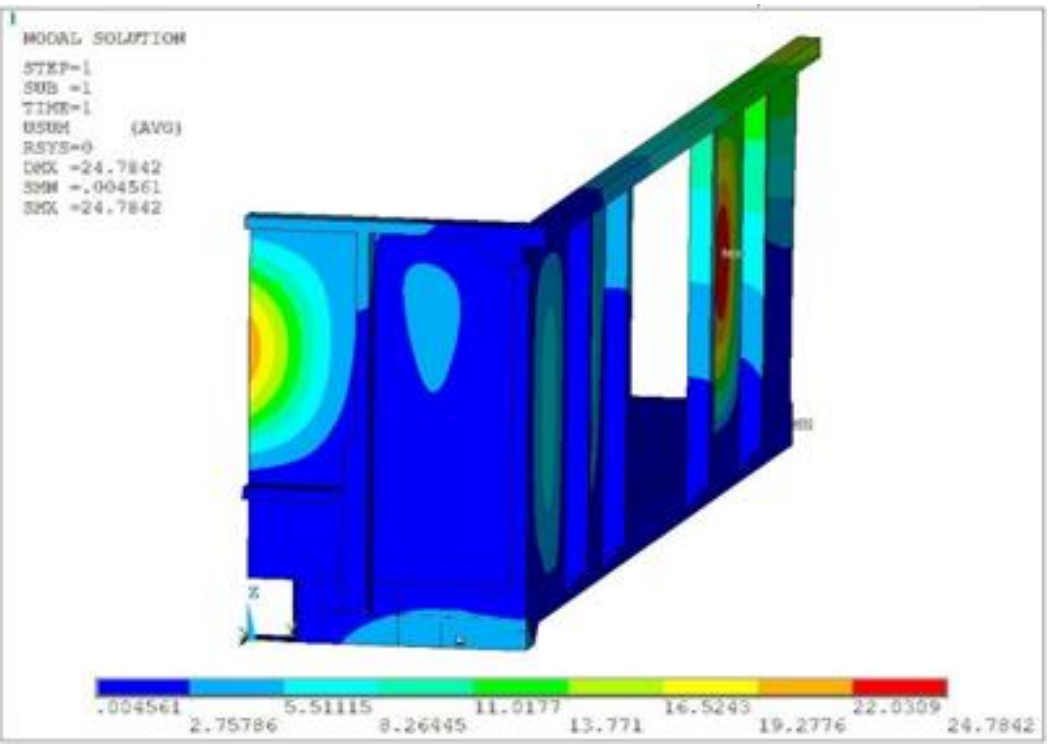

Figure 22.

Distribution of the total displacement for $10 \mathrm{~mm}$ thickness composite walls

In the case of $15 \mathrm{~mm}$ thickness composite walls, the results are shown in Figures 23 - 25. Increasing the thickness of the composite walls contributes to the decrease of the maximum displacement and the maximum value of the equivalent stress. Also, the total mass of the vehicle is greater compared to the previous case: only a $557 \mathrm{~kg}$ reduction compared to the mass of the steel walls is obtained in this case. 


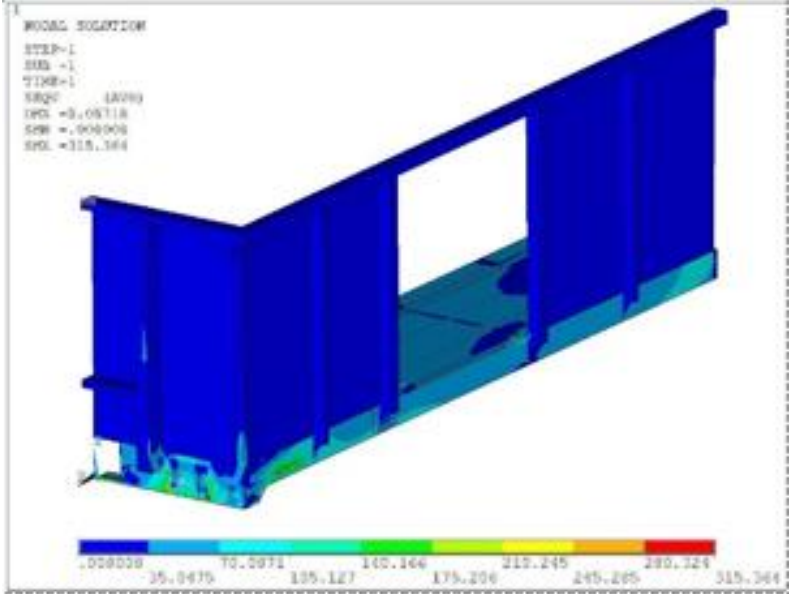

Figure 23. Von Mises stress distribution for $15 \mathrm{~mm}$ thick composite walls

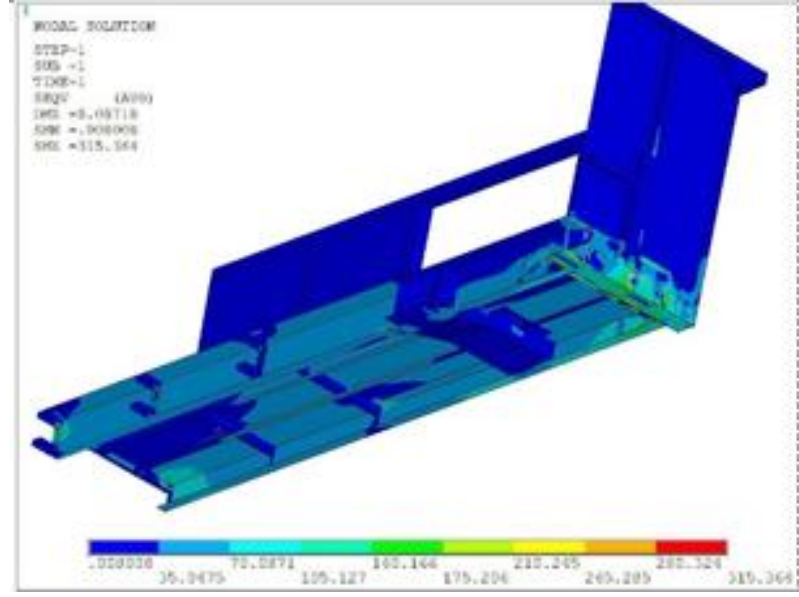

Figure 24. Von Mises stress distribution in the chassis area for $15 \mathrm{~mm}$ thick composite walls

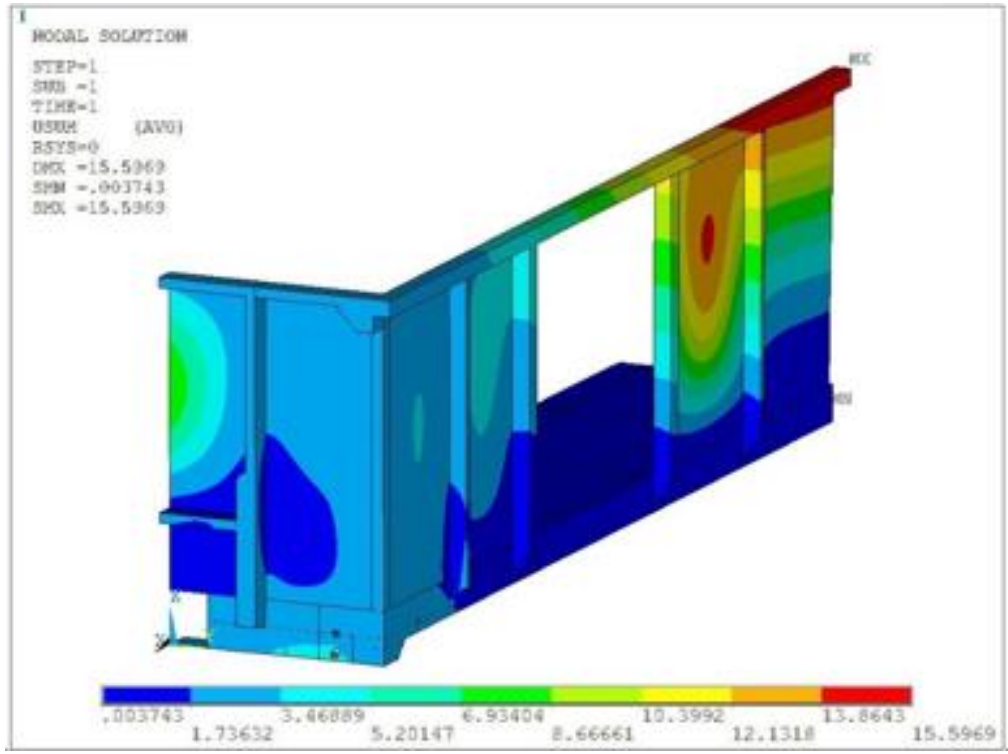

Figure 25. Distribution of the total displacement for $15 \mathrm{~mm}$ thick composite

\section{Conclusions}

Starting from the trend that characterizes the railway freight transport system, respectively the increase of the transported masses and of the traffic speed, this work aims at verifying the possibility of reducing the mass of a freight wagon by replacing the steel walls with walls made of composite materials.

Numerical analyses were performed to prove that the structure of the vehicle is not affected after the removal of the steel sheet from the walls. Further, the optimum thickness of the new composite walls was evaluated by finite element analyses on a $1 \mathrm{~m} \times 1 \mathrm{~m}$ square plate subjected to a $1 \mathrm{t} / \mathrm{m}^{2}$ pressure generated by the load of the vehicle. It was concluded that the optimum thickness of the composite material that can be used is at least $10 \mathrm{~mm}$, since a smaller thickness can lead to unacceptable high displacements. Starting from this conclusion, numerical analyses were carried out on a quarter of the vehicle structure for the most challenging loading case (compressive force at the buffers level), for two values of thickness, namely $10 \mathrm{~mm}$ and $15 \mathrm{~mm}$. Following the analysis, it was concluded that the use of composite material with a thickness of at least $10 \mathrm{~mm}$ instead of steel may be a feasible solution to reduce the mass of this type of vehicle, by replacing the steel sheet walls.

In the case of the transport of palletized goods, composite plates with thicknesses of less than $10 \mathrm{~mm}$ can be used: palletized goods loaded in the wagon do not exert pressure on the walls. In this case, the only role of the walls is to cover the structure of the wagon. 
For the case of composite plates with a thickness of $10 \mathrm{~mm}$, the mass of the vehicle is $820 \mathrm{~kg}$ lighter, which means an extra load of almost $1 \mathrm{t}$. As the average life of the vehicle can be 40 years or more [16], this reduction of mass contributes to the transport of thousands of tons of extra cargo during its lifetime. Figure 26 illustrates the evolution of the mass of goods which can be supplementary loaded due to the reduction of vehicle mass by replacing the steel walls with composite ones. In this graph, values of thickness starting from $5 \mathrm{~mm}$ were considered since thicknesses smaller than $10 \mathrm{~mm}$ can be used in the case of transport of palletized goods.

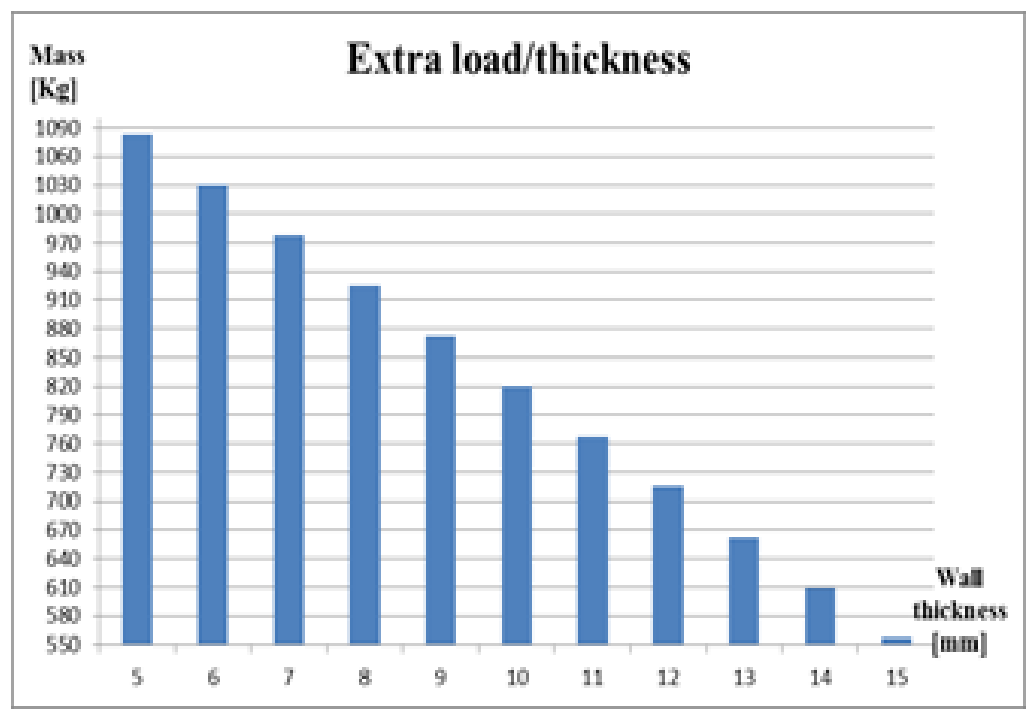

Figure 26. Variation of mass of supplementary load as a function on wall thickness

Another advantage of this constructive solution is the ease of application by gluing the plates on the steel poles of the vehicle body and eliminating thus the time lost for welding the steel plates. The main disadvantage of the presented constructive solution is the cost, the composite materials being much more expensive than steel. In some cases, composite sheets of different thickness can be used in combination, for the purpose of safely supporting the load. For example, thicker panels can be mounted at the bottom of the vehicle box to support the pressure of transporting bulk goods, while, at the top, panels with smaller thickness can be mounted in order to reduce the vehicle mass.

\section{References}

1.SEBEŞAN, I., Dinamica vehiculelor feroviare (Dynamics of Railway Vehicles), MatrixRom, Bucharest, Romania, 2011 (in Romanian).

2.PŁACZEK, M., WRÓBEL, A., BUCHACZ, A., A Concept of Technology for Freight Wagons Modernization, IOP Conf. Series: Materials Science and Engineering, 161, 2016, DOI:10.1088/1757899X/161/1/012107

3. WRÓBEL, A., PŁACZEK, M., BUCHACZ, A., Testing of Composite Panels Used as Components of a Freight Wagon by Thermovision, Acta Mechanica et Automatica, 10(1), 2016, 17-21.

4.PŁACZEK, M., WRÓBEL, A., BAIER, A., Computer-aided Strength Analysis of modernized freight wagon, IOP Conf. Series: Materials Science and Engineering, 95, 2015, DOI:10.1088/1757899X/95/1/012042.

5.BUCHACZ, A., BAIER, A., HERBUŚ, K., OCIEPKA, P., GRABOWSKI, Ł., SOBEK, M., Compression studies of multi-layered composite materials for the purpose of verifying composite panels model used in the renovation process of the freight wagon's hull, Eksploat Niezawodn, 20(1), 2018, 137-146. 
6. BUCHACZ, A., BAIER, A., HERBUŚ, K., OCIEPKA, P., An investigation of the influence of a fiber arrangement of a laminate on the values of stresses in the composite panel of a modified freight wagon using the FEM method, MATEC Web of Conferences 112, 2017, DOI: 10.1051/matecconf/ 201711204015.

7. KOSOBUDZKI, M., JAMROZIAK, K., BOCIAN, M., KOTOWSKI, P., ZAJĄC, P. - The Analysis of Structure of the Repaired Freight Wagon, AIP Conference Proceedings 2029, 2018, https://doi.org/10.1063/1.5066492.

8.SOBEK, M., BAIER, A., GRABOWSKI, Ł., MAJZNER, M., Fatigue test of a fiberglass based composite panel. Increasing the lifetime of freight wagon, IOP Conf. Series: Materials Science and Engineering, 145, 2016, DOI:10.1088/1757-899X/145/3/032008.

9. BÜHLER, S., Methods and Results of Field Testing of a Retrofitted Freight Train with Composite Brake Blocks, J. Sound Vib., 293, 2006, 1041-1050.

10.KRISTENSEN, R.F., NIELSEN, K.L., MIKKELSEN, L.P., Numerical studies of shear damped composite beams using a constrained damping layer, Compos. Struct., 83, 2008, 304-311.

11.BERCEANU, F., Compendium de vagoane de marfă. Marcaje, caracteristici, reglementări, echipamente (Compendium of freight wagons. Marks, characteristics, regulations, equipment), ASAB, Bucharest, Romania, 2002 (in Romanian).

12. *** EN 12663-2:2010. Railway application. Structural requirements of railway vehicle bodies - Part 2: Freight wagons, European Committee for Standardization, April 2010.

13. ANSYS 14.5 release notes, ANSYS Inc, Canonsburg, PA, USA, 2012.

14. PĂTRAȘCU, A. I., ZAHARIA, N. L., HADĂR, A., Analiza cu elemente finite a structurii portante a unui vehicul feroviar destinat transportului de marfă (Finite elements analysis of the carrying structure of a freight rail vehicle), MatrixRom, Bucharest, Romania, 2017 (in Romanian).

15. DRAGHICI, S., PARAUSANU, I., BACIU, F., PETRESCU, H.A., HADAR, A., PASTRAMA, S.D., A Comparative Experimental - Numerical Analysis on the Vibration Behaviour of a Composite Satellite Subset, Mater. Plast., 53(4), 2016, 585-589.

16.***Environment. (2019, February 08). Retrieved May 25, 2020, from https://ec.europa.eu/transport/ modes/rail/environment_en.

$\overline{\text { Manuscript received: } 26.05 .2020}$ 